\title{
Prevalence of double burden on malnutrition at household level in four Latin America countries
}

Hanrieti Rotelli Temponi 1

https://orcid.org/0000-0002-2534-0082

Gustavo Velasquez-Melendez 2

iD https://orcid.org/0000-0001-8349-5042

1,2 Escola de Enfermagem. Departamento de Enfermagem Materno Infantil e Saúde Pública. Universidade Federal de Minas Gerais. School of Nursing. Department of Maternal and Child Nursing and Public Health. Federal University of Minas Gerais. Avenida Alfredo Balena, 190. Santa Efigênia. Belo Horizonte, MG, Brasil. CEP: 30.130100. E-mail: hanrietirari@gmail.com

\begin{abstract}
Objectives: to estimate the prevalence of maternal overweight and short stature in children at household level in Brazil, Bolivia, Colombia and Peru.

Methods: a cross-sectional descriptive study. Population-based studies on children (0-5 years old) and women (15 to 49 years old) who participated in the Pesquisa Nacional de Demografia e Saúde da Criança e da Mulher(National Survey on Children and Women Demography and Health) in Brazil and the Encuesta Nacional de Demografía y Salud, (National Survey on Demography and Health), in Bolivia, Colombia and Peru. Variables of interest: overweight mother and child with short stature, a double burden when both outcomes are present. Global prevalence and stratification, according to rural and urban areas and 95\% confidence intervals, were estimated.

Results: the global sample consisted of 26,506 households. The prevalence of double burden was $9.3 \%$ in Bolivia (CI95\%=8.3-10.4), 6.7\% in Peru (CI95\%=5.9-7.5), Colombia (3.2\%; $C 195 \%=2.8-3.6)$ and Brazil (2.2\%; CI95\%=1.4-3.2). The highest prevalence were observed in the rural areas in Bolivia (13\% vs 6.5\%; $p<0.001)$ and Peru (11.9\% vs $4.1 \%$; $p<0.001$ ).

Conclusions: the highest prevalence were registered in Peru and Bolivia, and the lowest in Brazil and Colombia.
\end{abstract}

Key words Child, Height-for-age, Overweight, Prevalence, Stunted growth

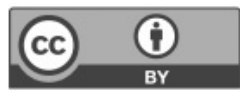




\section{Introduction}

The Brazilian population has experienced a rapid process of epidemiological and nutritional transition. In this context, non-transmittable chronic diseases are responsible for approximately $80 \%$ of causes of death in the Americas. ${ }^{1}$ Similarly, there was an increase in the prevalence of obesity, estimated at $20 \%, 2$ greater than the $13 \%$ calculated worldwide. 1 Studies report a $58 \%$ prevalence of overweight in Latin America, ${ }^{2}$ reaching a difference of 10 percentage points between men and women in more than 20 countries. ${ }^{2}$ Furthermore, it is estimated that in 2010, 3.4 million deaths worldwide were attributed for being overweight. ${ }^{3}$

Previous researches have shown that the economic development of countries in general has been accompanied by the changes in the population's lifestyle. The changes have led to a reduction in the level of physical activity and an increase in the consumption of highly energetic food, 4,5 which may explain the significant increase in overweight. In this context, short stature in child continues to be a public health problem. Studies show that short stature in children is associated with approximately half of children's deaths under the age of five worldwide. 1

Thus, there was a characterization of existence of a double burden of nutritional outcomes, maternal overweight and short stature in children has been described as a phenomenon related to the epidemiological changes experienced in an accelerated manner in low and middle income population countries. 6 Analyzes describes factors, as maternal as to children's socioeconomic, in addition to biological, genetic and nutritional factors, which are key determinants of short stature in children. 7,8 In 2016, the prevalence of this event was still $12 \%$ in Latin American countries and the Caribbean. ${ }^{9}$

Some determinants of short stature may appear to be distinct from overweight determinants. However, there is evidence that biological, environmental and socioeconomic factors that contribute to both the risk or prevalence of short stature, may also contribute to excess maternal weight, simultaneously. 1,5

The presence of short stature in children and maternal overweight from the same family has been observed in the literature, especially in places suffering from poor economic development. 10-12 For example, Argentina 10 and Guatemala, ${ }^{11}$ have reported prevalence rates of $12 \%$ and $17 \%$, respectively. Another study was carried out by using data from 42 countries (27 from Africa, 8 from Latin
America and 7 from Asia) evidenced a prevalence of double burden greater than $10 \%$ in Egypt, Bolivia, Guatemala and Peru. The research demonstrated that the main component of double burden in Latin America was overweight, while in African and Asian populations was short stature. ${ }^{12}$ In Brazil, the prevalence of double burden presents strong regional differences. ${ }^{13,14}$ In Colombia, double burden was $5.1 \%$, including other outcomes such as anemia. 15

In general, overweight and short stature in children are approached as events of independent determinants, however, they must be understood as a result of common determinants. ${ }^{6}$ Short stature in children can be a predisposing factor for being overweight in adulthood, ${ }^{16}$ which is associated with the development of certain types of cancer, cardiovascular diseases, type II diabetes and other metabolic disorders. 6 Therefore, it is necessary to understand the magnitude of the paradoxical coexistence of unsatisfactory nutritional outcomes, which impacts throughout the life cycle.6,16

Thus, this study aims to estimate the prevalence of maternal overweight and short infant stature (double burden on nutritional outcomes) in the mother-child binomial in Brazil, Bolivia, Colombia and Peru, using available population data for each of these countries. Household surveys present a broad set of indicators for planning, monitoring and impact assessment in the areas of population, health and nutrition of women and children in developing countries. 17 In addition to the representative samples used in these studies, the surveys allow to guarantee national representativeness and research comparability. 18

\section{Methods}

This is a descriptive and cross-sectional study, which used data from four population-based surveys conducted in the countries of South America: the Pesquisa Nacional de Demografia e Saúde da Criança e da Mulher (PNDS) (National Survey on Children and Women Demography and Health), conducted in Brazil between 2006 and 2007,19 and the Encuesta Nacional de Demografia y Salud, (ENDSA) held in Bolivia in 2008,20 in Colombia (ENDS) between 2009 and 2010,21 and in Peru (ENDES), during 2012.22

The four databases are part of the DHS Measure project (Demographic and Health Survey), whose investigations are conducted on a global scale, with the support from the United States Agency for Development (USAID), in partnership with other international institutions. 23 
For the construction of the final database in Brazil, based on the PNDS, data relating to Households, Women, Pregnancies and Children were done, as described in a previous study. ${ }^{17}$ In the case of Bolivia, Colombia and Peru, we used databanks referring to the individual questionnaires on Women, which present data corresponding to their children under the age of five. The inclusion of some available variables in the database on Households is highlighted, using those variables that code each residence.

In Brazil, data from the PNDS were collected between November 3, 2006 and May 3, 2007. A total of 14,617 selected households and 15,575 women aged, 15 to 49 years old were interviewed. ${ }^{19}$ In Bolivia, data from ENDSA were collected from February to June 2008. Of the 20,003 households selected, 16,939 women, aged 15 to 49 years old were interviewed. 20 In Colombia, data from ENDS were collected from November 2009 to November 2010 , so that 51,447 households were selected and 49,818 women were interviewed.21 Finally, in Peru, data from ENDES were collected from March to December 2012. A total of 27,488 households were selected and 23,888 women were interviewed.22

The data collection was carried out by trained teams following standardized protocols, in order to guarantee the quality of the information collected and the international comparability of the data. 23 However, although the questionnaires are standardized, some variables were specific for each country. Thus, the variables of common interest for the four countries were used for data analysis.

The selection criteria included the population of women, aged 15 to 49 years old, with their children under 60 months ( 5 years old). In cases where the mother had more than one child under the age of five, the oldest of them was considered for analysis. Pregnant women or women with a BMI $<18.5$, twin children and those with implausible stature/age values were excluded from the analysis. Women and children with incomplete data on variables of interest were not considered.

The outcome variable was obtained from the combinations of the following conditions: mother with or without excess weight and child with or without short stature. The simultaneous presence of maternal overweight and short stature of the child was defined as a double burden.

Overweight was considered as a Body Mass Index (BMI) $\geq 25 \mathrm{~kg} / \mathrm{m}^{2}$. BMI was calculated using the following formula: weight/height 2 . The children's low stature was defined by the height/age indicator z-score (HAZ). In addition, we considered
$\mathrm{HAZ}$ as a value of $<-2$ standard deviations (SD). ${ }^{18}$

For the description of the studied populations, the frequencies and $95 \%$ confidence intervals (CI) of the following variables were estimated: age ( $\geq 24$ months and $<24$ months), sex (male and female) and short stature in children (no and yes); age ( $\geq 25$ and $<25$ years) and maternal BMI ( $<25$ and $\left.\geq 25 \mathrm{~kg} / \mathrm{m}^{2}\right)$; and double burden of nutritional outcomes. Graphs were constructed with the prevalence and $95 \%$ confidence interval on nutritional outcomes (short stature in children, maternal overweight and double burden) for each country. A graph was also constructed with the prevalence and the $95 \%$ confidence interval of the double burden (short stature in children and maternal overweight). As this is the variable of greatest interest for this study, only the double burden was stratified by urban and rural areas in each country. The differences between the strata whose chi-square test presented $p<0.05$ were considered significant.

The data were analyzed using the STATA program version 13.1.24 An unconditional analysis of subpopulations was carried out, including exclusions. 25 As this is a complex sampling plan, unconditional analysis has a greater potential to correctly estimate standard errors. 25

The surveys were approved by the respective ethics committees in each country. All the participants received information about the objective of the research and their rights, and then asked to sign an Informed Consent Form. After the investigation and the release of the final report, the databases were made available for the public domain, on the Internet, and can be accessed by anyone who is interested, at the following websites: $<$ http://bvsms.saude.gov.br/bvs/pnds/index.php $>$ and $<$ https://dhsprogram.com/data/availabledatasets.cfm>.

\section{Results}

Table 1 shows the losses of mother-child binomials from the different countries studied after the eligibility criteria were implemented.

Results from the four countries showed that about $60 \%$ of the children were 24 months old or older and $50 \%$ were male. Regarding the age of women, approximately $60 \%$, in Brazil and Colombia, and $70 \%$, in Bolivia and Peru, were 25 years old or older. About $40 \%$ of the women had a $\mathrm{BMI} \geq 25 \mathrm{~kg} / \mathrm{m}^{2}$ (overweight) in the four countries. The prevalence of short stature in children was $5.6 \%$ $(\mathrm{CI} 95 \%=4.2-7.5)$ in Brazil, 20.4\% (CI95\% $=18.7$ $22.2)$ in Bolivia, $8.1 \% \quad(\mathrm{CI} 95 \%=7.5-8.8)$ in 
Summary of the study data: initial number of women and children, number of losses and final sample size in Brazil, Bolivia, Colombia and Peru.

\begin{tabular}{lcccc}
\hline & Brazil & Bolivia & Colombia & Peru \\
\hline $\begin{array}{l}\text { Sample size of women } 15 \text { to } 49 \text { years of age } \\
\text { and their children up to } 60 \text { months of age }\end{array}$ & 4,882 & 8,091 & 16,939 & 9,187 \\
Mother-child binomial losses & & & & \\
$\quad$ By exclusion criteria - Stage 1 & 1,873 & 2,697 & 4,990 & 1,954 \\
$\quad$ Lack of information - Stage 2 & 345 & 31 & 482 & 221 \\
Final sample & 2,664 & 5,363 & 11,467 & 7,012 \\
& & & & \\
\hline
\end{tabular}

Colombia, and $12.5 \%($ CI95\%=11.4-13.6) in Peru. In relation to the double burden, a prevalence of $2.2 \%(\mathrm{CI} 95 \%=1.47-3.2)$ was observed in Brazil, $9.3 \% \quad(\mathrm{CI} 95 \%=.3-10.4) \quad$ in Bolivia, $3.2 \%$ $(\mathrm{CI} 95 \%=2.8-3.6)$ in Colombia, and $6.7 \%$ $(\mathrm{C}$ 95\% $\%=6.0-7.5)$ in Peru (Table 2$)$.

Figure 1 shows the prevalence of nutritional outcomes for the four studied countries. In Peru, the prevalence of maternal overweight was greater than $50 \%(53.2 \%$; CI95\%=51.5-54.8), followed by Bolivia (43.4\%; CI95\%=41.3-45.5), Colombia (42.7\%; CI95\%=41.5-43.9) and Brazil (41.1\%; $\mathrm{CI} 95 \%=37.8-44.5)$. In Brazil, the prevalence of short stature in children was $3.5 \%(\mathrm{CI} 95 \%=2.4-4.9)$. In Bolivia, the prevalence of this condition was $11.1 \%$ $($ CI95\% $=9.9-12.4)$, which was greater than Colombia (5.0\%; CI95\%=4.4-5.5). Peru, in turn, had a higher prevalence when compared to Colombia $(5.8 \%$; CI95\% $=5.2-6.6)$.

The general prevalence of double burden was $2.2 \%$ in Brazil (CI95\% $=1.4-3.2), 3.2 \%$ in Colombia $(\mathrm{CI} 95 \%=2.8-3.6), 6.7 \%$ in Peru $(\mathrm{CI} 95 \%=5.9-7.5)$ and $9.3 \%$ in Bolivia (CI95\%=8.3 10.4).

Figure 2 shows the prevalence of double burden, considering the area of residence. The double burden were more prevalent in the rural areas in Bolivia $(13 \%, \mathrm{CI} 95 \%=11.4-14.8$, in rural areas versus $6.5 \%$, $\mathrm{CI} 95 \%=5.4-7.9$, in urban areas; $p<0.001)$ and Peru $(11.9 \%, \mathrm{CI} 95 \%=10.4-13.5$, in rural area $v s 4.1 \%$, CI95\% $=3.4-4.9$, in the urban area; $p<0.001)$. In the rural area in Brazil, the prevalence of double burden was similar to those found in the urban area of Colombia. In the rural area in Colombia, the prevalence of double burden was similar to those found in the urban area of Peru. Bolivia and Peru which had a similar prevalence of double burden in the rural area. However, Bolivia has a greater prevalence of double burden in the urban area.

It should be pointed out that in Bolivia, the prevalence of double burden in the rural area is twice as of the urban area. In Peru, this difference is even greater, with the prevalence of double burden in rural areas as it is almost three times more than in the urban ones. In Colombia, the prevalence found was $3.0 \%(\mathrm{CI} 95 \%=2.5-3.5)$ in the urban area and $3.6 \%$ $(\mathrm{CI} 95 \%=2.9-4.5)$ in the rural area. In Brazil, it was $2.0 \%(\mathrm{CI} 95 \%=1.3-3.3)$ in the urban area and $2.7 \%$ $(\mathrm{CI} 95 \%=1.6-4.4)$ in the rural. However, the prevalence of double burden did not differ statistically between rural and urban areas in Brazil and Colombia ( $p=0.43$ and 0.19 , respectively).

\section{Discussion}

This study estimated the prevalence of double burden, maternal overweight and short stature in children in household level in four Latin American countries. The greatest prevalence of double burden were observed in Bolivia and Peru. In Colombia, the prevalence of double burden was similar to Brazil. When the data were categorized by area of residence, the four countries had the highest double burden in the rural areas: Bolivia and Peru had the greatest prevalence, followed by Colombia and Brazil. Small urban/rural differences were observed in the populations of Brazil and Colombia, which were not statistically significant. In Peru and Bolivia, however, urban/rural differences stood out as statistically significant.

Previous studies carried out in Latin American countries observed greater prevalence than those observed in Bolivia and Peru. Data analysis from a representative sample of a Guatemalan population (The Guatemala Living Standards Measurement Survey) of mothers and their children aged 6 to 60 months old, confirmed the prevalence of a double burden of $17 \% .11$ Another study, carried out in regions of Argentina with children over two years of 
Table 2

\begin{tabular}{|c|c|c|c|c|c|c|c|c|c|c|c|c|}
\hline \multirow[t]{2}{*}{ Variables } & \multicolumn{3}{|c|}{ Brazil } & \multicolumn{3}{|c|}{ Bolivia } & \multicolumn{3}{|c|}{ Colombia } & \multicolumn{3}{|c|}{ Peru } \\
\hline & $\mathrm{n}$ & $\%$ & $\mathrm{Cl} 195 \%$ & $\mathrm{n}$ & $\%$ & $\mathrm{Cl} 95 \%$ & $\mathrm{n}$ & $\%$ & C195\% & $\mathrm{n}$ & $\%$ & $\mathrm{Cl} 95 \%$ \\
\hline Population sample* & 2,664 & & & 5,363 & & & 11,467 & & & 7,012 & & \\
\hline \multicolumn{13}{|l|}{ Child's gender } \\
\hline Male & 1,360 & 52.0 & $48.9-55.2$ & 2,710 & 50.6 & $48.9-52.3$ & 5,900 & 51.7 & $50.4-52.9$ & 3,533 & 50.8 & $49.3-52.2$ \\
\hline Female & 1,304 & 48.0 & $44.8-51.1$ & 2,653 & 49.4 & $47.8-51.1$ & 5,567 & 48.3 & $47.1-49.6$ & 3,479 & 49.2 & $47.8-50.7$ \\
\hline \multicolumn{13}{|l|}{ Child's age (months) } \\
\hline$\geq 24$ & 1,788 & 63.6 & $60.4-66.8$ & 3,664 & 68.6 & $67.0-70.1$ & 7,724 & 67.2 & $66.1-68.3$ & 4,738 & 66.7 & $65.2-68.1$ \\
\hline$<24$ & 876 & 36.4 & $32.2-39.6$ & 1,699 & 31.4 & $29.9-33.0$ & 3,743 & 32.8 & $31.7-33.9$ & 2,274 & 33.3 & $31.9-34.8$ \\
\hline \multicolumn{13}{|l|}{ Mother's age (years) } \\
\hline$\geq 25$ & 1,719 & 61.0 & $57.4-64.4$ & 3,767 & 71.9 & $70.5-73.4$ & 7,339 & 65.4 & $64.2-66.6$ & 5,091 & 73.3 & $71.7-74.8$ \\
\hline$<25$ & 945 & 39.0 & $35.6-42.6$ & 1,596 & 28.1 & $26.6-29.5$ & 4,128 & 34.6 & $33.4-35.8$ & 1,921 & 26.7 & $25.2-28.3$ \\
\hline \multicolumn{13}{|l|}{ Maternal BMI** } \\
\hline$<25 \mathrm{~kg} / \mathrm{m}^{2}$ & 1,510 & 56.7 & $53.5-59.9$ & 2,560 & 47.3 & $45.4-49.2$ & 6,089 & 54.2 & $53.0-55.4$ & 2,898 & 40.2 & $38.6-41.7$ \\
\hline$\geq 25 \mathrm{~kg} / \mathrm{m}^{2}$ & 1,154 & 43.3 & $40.1-46.5$ & 2,803 & 52.7 & $50.8-54.6$ & 5,378 & 45.8 & $44.6-47.0$ & 4,114 & 59.8 & $58.3-61.4$ \\
\hline \multicolumn{13}{|l|}{ Child' height by age } \\
\hline No & 2,515 & 94.4 & $92.5-95.8$ & 4,299 & 79.6 & $77.8-81.3$ & 10,367 & 91.9 & $91.2-92.5$ & 6,007 & 87.5 & $86.4-88.6$ \\
\hline Yes & 149 & 5.6 & $4.2-7.5$ & 1,064 & 20.4 & $18.7-22.2$ & 1,100 & 8.1 & $7.5-8.8$ & 1,005 & 12.5 & $11.4-13.6$ \\
\hline \multicolumn{13}{|l|}{ Double burden*** } \\
\hline No & 2,595 & 97.8 & $96.8-98.5$ & 4,880 & 90.7 & $89.6-91.7$ & 11,037 & 96.8 & $96.4-97.2$ & 6,502 & 93.3 & $92.5-94.0$ \\
\hline Yes & 69 & 2.2 & $1.47-3.2$ & 483 & 9.3 & $8.3-10.4$ & 430 & 3.2 & $2.8-3.6$ & 510 & 6.7 & $6.0-7.5$ \\
\hline
\end{tabular}

* Complex sample plan. Corresponds to the total number of mother-child binomials considered for analysis in the survey, but without the post-stratification of weights; ${ }^{* *} \mathrm{BMI}=$ Body Mass Index; ${ }^{* *}$ Overweight mother and short stature in children.

age and their mothers, reported a prevalence of $12 \% .10$ Surveys conducted in Asian countries observed even higher prevalence, such as in Malaysia, at $19.4 \%, 26$ and in Bandung, Indonesia, which reached $30.6 \% .27$

It is worth noting that the prevalence of maternal overweight among the studied populations was similar, affecting more than $40 \%$ of the women. Regarding short stature by age, the prevalence ranged from $3.5 \%$ in Brazil to $11.1 \%$ in Bolivia. This finding demonstrates that the prevalence of double burden possesses a main component of short stature in children. Hence, the magnitude of the prevalence of double burden suggests a chronic socioeconomic deprivation situation, expressed by negative environmental influences on children's health and reflecting on low socioeconomic level conditions and the development of a country 8 and to the context of nutritional transition in these populations.

Over the past decades, there was a decline in the prevalence of short stature among Brazilian children under the age of five, which explains in some way the low prevalence of double burden in Brazil. This result was attributed to several factors, such as urbanization, increased maternal schooling, expanding access to health services, increased population income and public social protection policies. 28 Currently, most Latin American countries are more intensely organized in the international markets, with consequent economic growth, which has made these countries increasingly more urbanized. 12 Thus, the relation between double burden and economic development is emphasized, since the double burden was more prevalent in families living in rural areas in Guatemala, which these families had worse socioeconomic conditions. ${ }^{11}$

In addition, from the analyzes of the present study, we observed that there is similarity between the prevalence of double burden in the following countries: Bolivia, Peru, Colombia, and Brazil. It is possible to relate these prevalence to the GDP (Gross Domestic Product) per capita that each country reported in the year in which its DHS was developed. Colombia and Brazil had higher values than Bolivia, but Peru had the greatest GDP per capita. Bolivia had the lowest GDP per capita, roughly $\$ 4,500$. In Peru, it was $\$ 10,900$ dollars. Colombia, in turn, had a GDP per capita of $\$ 9,800$ and Brazil, 


\section{Figure 1}

Prevalence and confidence interval of the double burden of mother-child binomial in Brazil, Bolivia, Colombia and Peru.
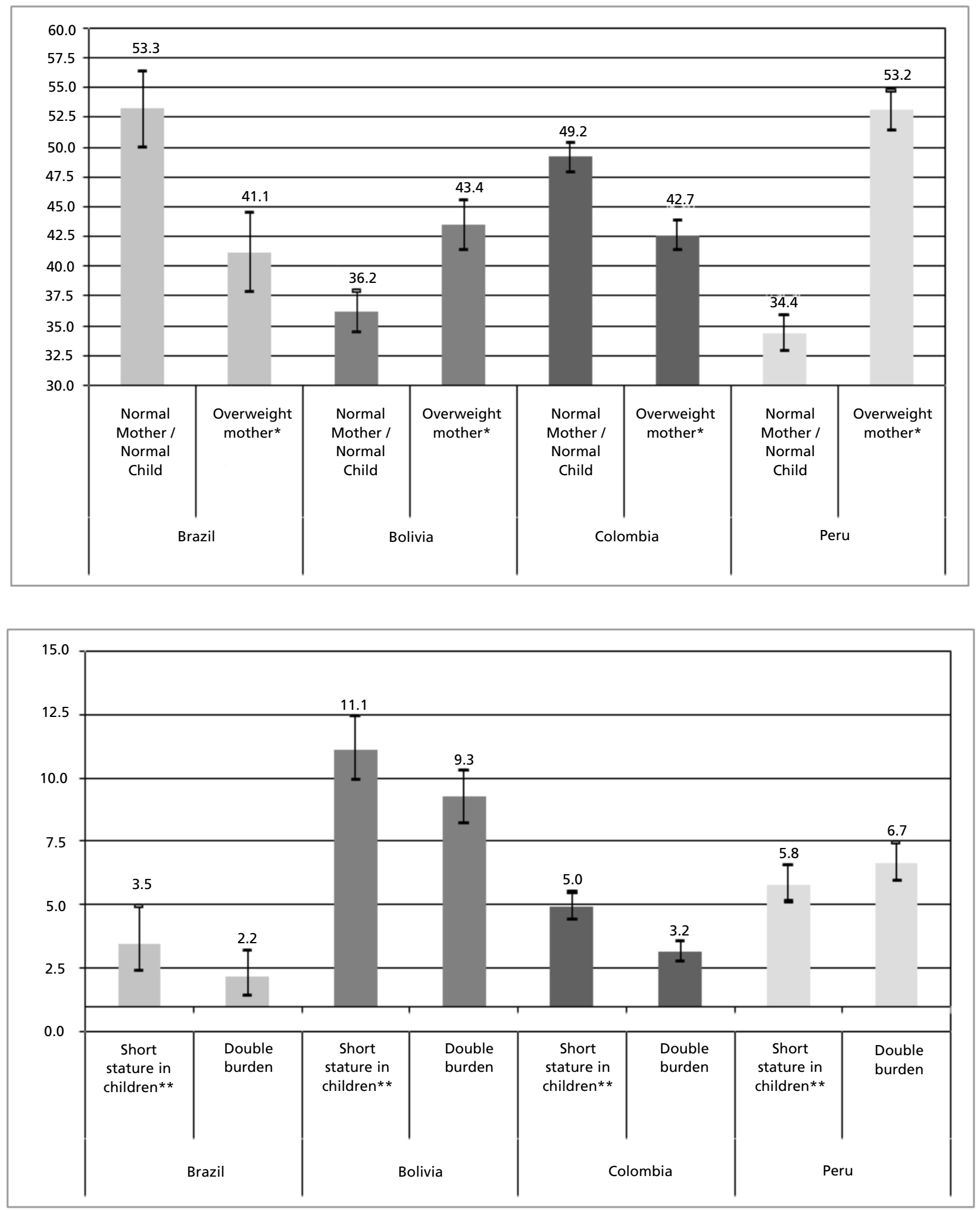

* Binomial on overweight mothers and children with normal height; **Binomial of eutrophic mothers and short stature in children. 
Figure 2

Prevalence and confidence interval of the double burden of the mother-child binomial in Brazil, Bolivia, Colombia and Peru according to the area of residence.

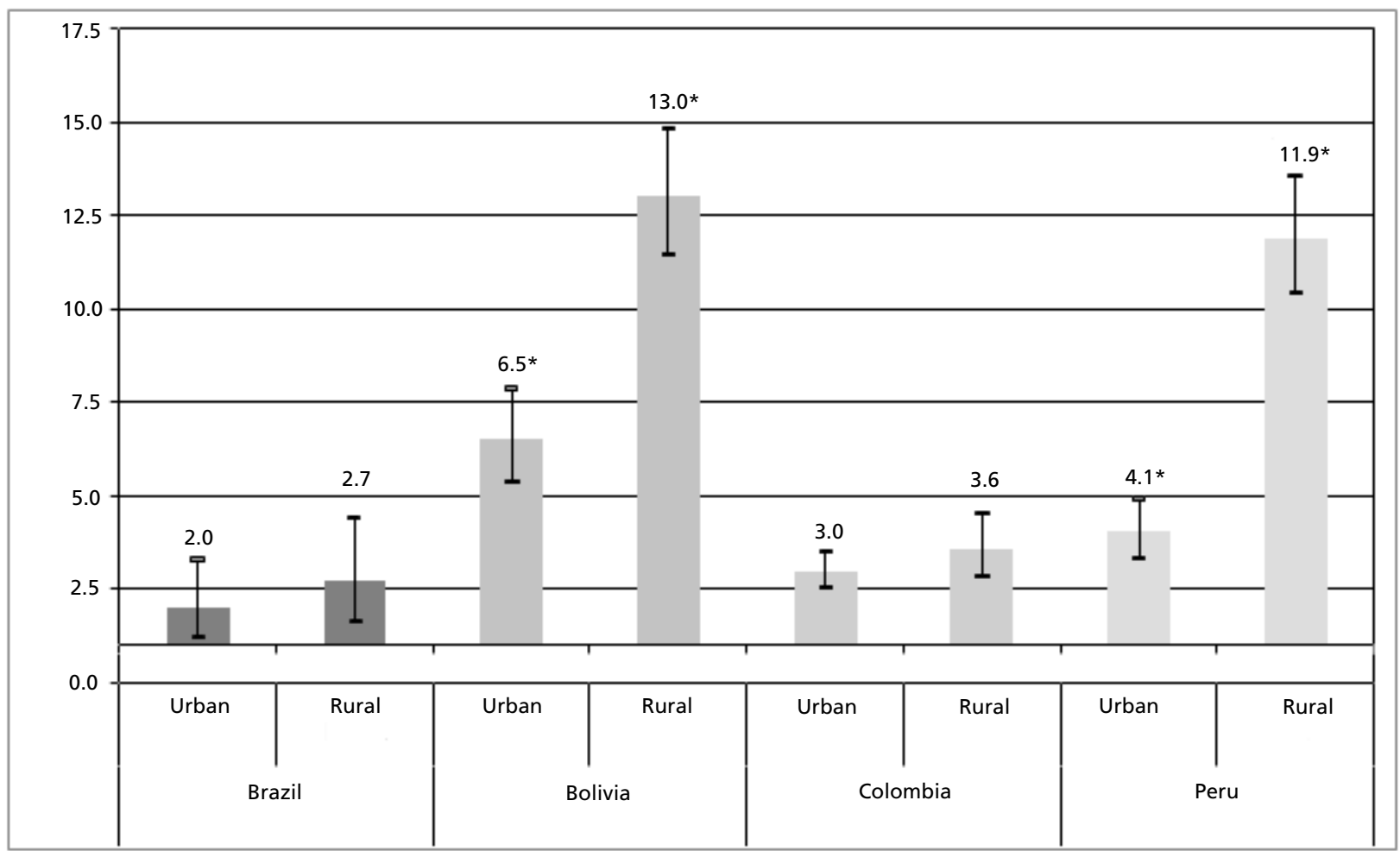

${ }^{*} p<0.05$

$\$ 8,800$ dollars. 29

However, GDP per capita, an indicator of the economic growth, is an average of the household income, making it necessary to consider social inequality for its best assessment. In addition, the health conditions in the country are the result of the economic growth associated with the improvement of factors which do not strictly linked to the income, 30 such as coverage on health services, education, sanitation and a potable water supply.

In the international reference population, the prevalence of short stature in children is $2.5 \%(\mathrm{z}-$ score $<=-2$ ) and the percentage of double burden found in countries like Brazil and Colombia were close to this value. Thus, contexts of economic development at the levels of these countries would be sufficient to achieve a prevalence of double burden below $5 \%$. The results of the present study highlight the importance of the government strategies and the public health service systems, which aim at determining the double burden of malnutrition. Therefore, it is important to develop research that identifies the factors associated with the double burden of the populations in these regions.

One of the limitations of the present study was the loss of samples due to missing data on the variables of interest. Individuals who presented loss of information were not included in the constructed indicator variables and, therefore, were not part of the analyzes. However, we emphasize that there were samples with national representativeness, which attests to their internal validity. Another limitation concerns the difference in the periods when surveys were carried out, which could make it difficult to compare the prevalence rates among the countries. However, the studied phenomenon does not change over the short periods of time, since the maximum difference among the countries is six years. In addition, the data used were the most current available in each country, which contains the necessary information for the present study.

The double burden of the disease, with the simultaneous presence of overweight and short stature can be considered as an indicator of low socioeconomic levels and, at the same time, a stage of accelerated nutritional transition. This last 
phenomenon can be explained by the relative change in food consumption habits attributed to the decrease in consumption of fresh food, replacing with more processed food, which have a high content of simple fats and sugars. The prevalence of this phenomenon would indicate the level of development that each population is experiencing. In Brazil and Colombia, the double burden can be considered low, and in the populations of Peru and Bolivia, they continue to show the prevalence rates are above $5 \%$, which is characterized as a public health problem in these same countries.

\section{Acknowledgements}

We would like to thank the Conselho Nacional de Desenvolvimento Científico e Tecnológico (CNPq) (National Council for Scientific and Technological Development) and the Fundação de Amparo a Pesquisa do Estado de Minas Gerais (FAPEMIG) (Research Support Foundation) for their financial contributions.

\section{References}

1. Hawkes C, Fanzo J. Nourishing the SDGs: Global Nutrition Report 2017. Bristol: Development Initiatives Poverty Research Ltd; 2017.

2. Organização das Nações Unidas para a Alimentação e a Agricultura e Organização Pan-Americana da Saúde. Panorama da Segurança Alimentar e Nutricional. Santiago; 2017.

3. Ng M, Fleming T, Robinson M, Thomson B, Graetz N, Margono C, Mullany EC, Biryukov S, Abbafati C, Abera SF, Abraham JP, Abu-Rmeileh NM, Achoki T, AlBuhairan FS, Alemu ZA, Alfonso R, Ali MK, Ali R, Guzman NA, Ammar W, Anwari P, Banerjee A, Barquera S, Basu S, Bennett DA, Bhutta Z, Blore J, Cabral N, Nonato IC, Chang JC, Chowdhury R, Courville KJ, Criqui MH, Cundiff DK, Dabhadkar KC, Dandona L, Davis A, Dayama A, Dharmaratne SD, Ding EL, Durrani AM, Esteghamati A, Farzadfar F, Fay DF, Feigin VL, Flaxman A, Forouzanfar MH, Goto A, Green MA, Gupta R, Hafezi-Nejad N, Hankey GJ, Harewood HC, Havmoeller R, Hay S, Hernandez L, Husseini A, Idrisov BT, Ikeda N, Islami F, Jahangir E, Jassal SK, Jee SH, Jeffreys M, Jonas JB, Kabagambe EK, Khalifa SE, Kengne AP, Khader YS, Khang YH, Kim D, Kimokoti RW, Kinge JM, Kokubo Y, Kosen S, Kwan G, Lai T, Leinsalu M, Li Y, Liang X, Liu S, Logroscino G, Lotufo PA, Lu Y, Ma J, Mainoo NK, Mensah GA, Merriman TR, Mokdad AH, Moschandreas J, Naghavi M, Naheed A, Nand D, Narayan KM, Nelson EL, Neuhouser ML, Nisar MI, Ohkubo T, Oti SO, Pedroza A, Prabhakaran D, Roy N, Sampson U, Seo H, Sepanlou SG, Shibuya K, Shiri R, Shiue I, Singh GM, Singh JA, Skirbekk V, Stapelberg NJ, Sturua L, Sykes BL, Tobias M, Tran BX, Trasande L, Toyoshima

\section{Authors' contribution}

Temponi HR performed the data acquisition and analysis, participated in the writing, interpretation of the results and the review of the article; VelasquezMelendez $\mathrm{G}$ defined the study design, participated in the writing, the interpretation of results and the review of this article. All authors approved the final version of the manuscript.

H, van de Vijver S, Vasankari TJ, Veerman JL, VelasquezMelendez G, Vlassov VV, Vollset SE, Vos T, Wang C, Wang $\mathrm{X}$, Weiderpass E, Werdecker A, Wright JL, Yang YC, Yatsuya H, Yoon J, Yoon SJ, Zhao Y, Zhou M, Zhu S, Lopez AD, Murray CJ, Gakidou E. Global, regional, and national prevalence of overweight and obesity in children and adults during 1980-2013: a systematic analysis for the Global Burden of Disease Study 2013. Lancet. 2014; 384 (9945): 766-81.

4. Andrade RG, Chaves OC, Costa DAS, Andrade ACS, Bispo S, Felicissimo MF, Friche AAL, Proietti FA, Xavier CC, Caiaffa WT. Overweight in men and women among urban area residents: individual factors and socioeconomic context. Cad Saúde Pública. 2015; 31 (Suppl. 1): 148-58.

5. Speakman JR, O'Rahilly S. Fat: an evolving issue. Dis Model Mech. 2012; 5 (5): 569-73.

6. WHO (World Health Organization). The double burden of malnutrition: policy brief. Geneva; 2017.

7. Akombi B, Agho K, Hall J, Wali N, Renzaho A, Merom D. Stunting. Wasting and Underweight in Sub-Saharan Africa: A Systematic Review. Int J Environ Res Public Health. 2017; 14 (8): 863 .

8. Oliveira FCC, Cotta RMM, Ribeiro AQ, Sant'Ana LFR, Priore SE, Franceschini SCC. Estado nutricional e fatores determinantes do déficit estatural em crianças cadastradas no Programa Bolsa Família. Epidemiol Serv Saúde. 2011; 20 (1): 7-18.

9. Institute for Health Metrics and Evaluation. Child Growth Failure Visualization - Input Data. Seattle; 2018. 
10. Bassett MN, Giménez MA, Lobo MO, Samman NC. Prevalencia y determinantes de la doble carga de malnutrición en hogares en La Puna y Quebrada de Humahuaca, Jujuy, Argentina. Nutr Hosp. 2014; 29 (2): 322-30

11. Lee J, Houser RF, Must A, de Fulladolsa PP, Bermudez OI. Socioeconomic disparities and the familial coexistence of child stunting and maternal overweight in Guatemala. Econ Hum Biol. 2012; 10 (3): 232-41.

12. Garrett JL, Ruel MT. Stunted Child-Overweight Mother Pairs: Prevalence and Association with Economic Development and Urbanization. Food Nutr Bull. 2005; 26 (2): 209-21.

13. Géa-Horta T, Felisbino-Mendes MS, Ortiz RJF, Velasquez-Melendez G. Association between maternal socioeconomic factors and nutritional outcomes in children under 5 years of age. J Pediatr. (Rio J.). 2016; 92 (6): 574 80

14. Gubert MB, Spaniol AM, Segall-Corrêa AM, PérezEscamilla R. Understanding the double burden of malnutrition in food insecure households in Brazil: Dual-burden malnutrition and food insecurity. Matern Child Nutr. 2017; 13 (3): 2347.

15. Sarmiento OL, Parra DC, González SA, GonzálezCasanova I, Forero AY, Garcia J. The dual burden of malnutrition in Colombia. Am J Clin Nutr. 2014; 100 (6): 1628S$35 \mathrm{~S}$.

16. Sawaya AL, Roberts S. Stunting and future risk of obesity: principal physiological mechanisms. Cad Saúde Pública. 2003; 19 (Suppl. 1): S21-8.

17. Felisbino-Mendes MS, Matozinhos FP, Miranda JJ, Villamor E, Velasquez-Melendez G. Maternal obesity and fetal deaths: results from the Brazilian cross-sectional Demographic Health Survey, 2006. BMC Pregnancy Childbirth. 2014; 14: 5 .

18. WHO (World Health Organization). WHO child growth standards: training course on child growth assessment. Geneva; 2008.

19. Brasil. Pesquisa Nacional de Demografia e Saúde da Criança e da Mulher - PNDS 2006: dimensões do processo reprodutivo e da saúde da criança. Centro Brasileiro de Análise e Planejamento. 2009; [acesso em 14 jul 2019] Disponível em: http://bvsms.saude.gov.br/bvs/publicacoes/pnds_crianca_mulher.pdf
20. Coa R, Ochoa LH. Bolivia Encuesta Nacional de Demografía y Salud - ENDSA - 2008. Ministerio de Salud y Deportes and Macro International. Calverton, Maryland; 2009.

21. Profamilia. Encuesta Nacional de Demografía y Salud 2010 (ENDS). Bogotá; 2010.

22. Perú. Instituto Nacional de Estadística e Informatica Perú (INEI). Encuesta demográfica y de salud familiar - ENDES 2012. Lima; 2012.

23. ICF. Demographic and Health Survey Interviewer's Manual. Rockville, Maryland: 2017; 20

24. Statacorp. College Station. TX; 2013.

25. West BT, Berglund P, Heeringa SG. A closer examination of subpopulation analysis of complex-sample survey data. Stata J. 2008; 8 (4): 520-31.

26. Wong CY, Zalilah MS, Chua EY, Norhasmah S, Chin YS, Siti Nur'Asyura A. Double-burden of malnutrition among the indigenous peoples (Orang Asli) of Peninsular Malaysia. BMC Public Health. 2015; 15: 680.

27. Sekiyama M, Jiang HW, Gunawan B, Dewanti L, Honda R, Shimizu-Furusawa H, Abdoellah OS, Watanabe C. Double Burden of Malnutrition in Rural West Java: HouseholdLevel Analysis for Father-Child and Mother-Child Pairs and the Association with Dietary Intake. Nutrients. 2015; 7 (10): 8376-91.

28. Conde WL, Monteiro CA. Nutrition transition and double burden of undernutrition and excess of weight in Brazil. Am J Clin Nutr. 2014; 100 (6): 1617S-22S.

29. CIA World Factbook. Historical Data Graphs per Year [Internet]. 2015 [acesso em 9 jan 2019]. Disponível em: https://www.indexmundi.com/g/g.aspx?v=65 \&c=bl\&l=pt

30. Monteiro CA, Benício MHD, Conde WL, Konno SC, Lima ALL, Barros AJD, Victora CG. Desigualdades socioeconômicas na baixa estatura infantil: a experiência brasileira, 1974-2007. Estud Av. 2013; 27 (78): 38-49.
Received on September 27, 2018

Final version presented on November 20, 2019

Approved on December 10, 2019 